\title{
NMR Studies and Conformational Energy Calculations of 1,2-Dimethoxyethane and Poly(oxyethylene)
}

\author{
Kenzabu TASAKI and Akihiro ABE \\ Department of Polymer Chemistry, Faculty of Engineering, \\ Tokyo Institute of Technology, Megro-ku, \\ Tokyo 152, Japan
}

(Received October 11, 1984)

\begin{abstract}
Conformational studies on 1,2-dimethoxyethane (DME), a monomer model compound of poly(oxyethylene), have been carried out by using NMR technique. The observed temperature dependence of the vicinal coupling constants was analyzed on the basis of the rotational isomeric state scheme. For the $\mathrm{C}-\mathrm{C}$ bond, the ${ }^{13} \mathrm{CH}$ satellite side bands provide the desired information. Conformational energy $E_{\sigma}$, representing the energy of the gauche state expressed relative to the trans, was found to vary in a range -0.5 to $-1.2 \mathrm{kcal} \mathrm{mol}^{-1}$, depending on the solvent system. Values of $J_{\mathrm{T}}$ and $J_{\mathrm{G}}$ for the vicinal ${ }^{1} \mathrm{H}-{ }^{1} \mathrm{H}$ coupling were determined concomitantly: $J_{\mathrm{T}}=11.4 \pm 0.3$ and $J_{\mathrm{G}}=2.3 \pm 0.1 \mathrm{~Hz}$. For the rotation about the $\mathrm{C}-\mathrm{O}$ bond, the vicinal ${ }^{13} \mathrm{C}-{ }^{1} \mathrm{H}$ coupling constant associated with the terminal methyl group was studied. Adoption of $J_{\mathrm{G}}=1.3 \mathrm{~Hz}$ leads to an estimate of $E_{\rho}=0.8$ to $1.1 \mathrm{kcal} \mathrm{mol}^{-1}$ for the energy difference between the gauche and trans states. In these treatments, the neighbor-dependent character of the bond rotation along the chain was rigorously taken into account. The values of $E_{\sigma}$ and $E_{\rho}$ derived for the polymer are comparable with those of DME. The results are compared with those reported previously by Viti et al. and Mastuzaki et al.
\end{abstract}

KEY WORDS 1,2-Dimethoxyethane / Poly(oxyethylene) $/{ }^{13} \mathrm{CH}$ Satellite NMR / ${ }^{13} \mathrm{C}$ NMR / Vicinal Coupling Constant / Potential Energy Calculation / Conformational Energy /

In a series of papers, ${ }^{1-3}$ we have investigated conformational characteristics of polyoxide chains having a general formula $\mathrm{fCH}_{2} \mathrm{C}$ $\left(\mathrm{R}_{1}\right)\left(\mathrm{R}_{2}\right) \mathrm{O}_{n}$, in which gauche $\mathrm{O} \cdots \mathrm{O}$ interactions take place around the skeletal $\mathrm{C}-\mathrm{C}$ bond. The major purpose of these studies is to evaluate the gauche oxygen effect associated with these polymers in terms of the extra stabilization energies, which have been defined as the difference between the conformational energies calculated by using conventional semiempirical expressions ${ }^{1}$ and those derived from the analysis of the experimental data on some relevant conformation-dependent properties such as the unperturbed dimension, dipole moment, and bond conformation. In the case of poly(oxyethylene) (POE), where $R_{1}=R_{2}=H$, the semiempirical energy calcula- tion $\left(0.6 \mathrm{kcal} \mathrm{mol}^{-1}\right)$ failed to reproduce the observed preference $\left(-0.4 \mathrm{kcal} \mathrm{mol}^{-1}\right)$ for the gauche over the trans state..$^{4.5}$ The discrepancy amounts to $c a$. $1 \mathrm{kcal} \mathrm{mol}^{-1}$. In the poly(oxypropylene) (POP) chain, ${ }^{2}$ two gauche states occurring around the skeletal $\mathrm{C}-\mathrm{C}$ bond are sterically unequivalent to each other. The gauche oxygen effect estimated for the $g_{\alpha}$ conformation, in which the articulated methyl group is situated trans to the preceding oxygen, is in the same order of magnitude as that of POE. Such a stabilization effect, however, was found to be largely suppressed in the sterically more hindered $g_{\beta}$ conformation, in which the preceding oxygen atom is syn to both the following oxygen and the methyl group. A value of $E_{\mathrm{g}}=0.5 \mathrm{kcal} \mathrm{mol}^{-1}$ (expressed relative to trans) was derived from the 
(a)

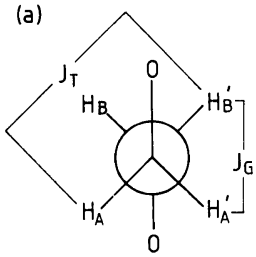

trans

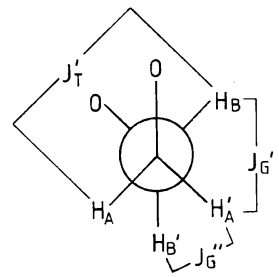

gauche (b)

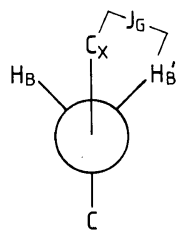

trans

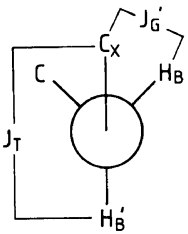

gauche

Figure 1. (a) The preferred conformations about the $\mathrm{C}-\mathrm{C}$ bond, and definition of the trans and gauche vicinal ${ }^{1} \mathrm{H}-{ }^{1} \mathrm{H}$ couplings. (b) Definition of the trans and gauche vicinal ${ }^{13} \mathrm{C}-{ }^{1} \mathrm{H}$ couplings for the $\mathrm{C}-\mathrm{O}$ bond.

NMR and dipole moment analysis on poly(oxy-1,1-dimethylethylene) (PODME) and its model compound. ${ }^{3}$ This value was favorably reproduced by the conformational energy calculation, indicating that the gauche oxygen effect is effectively nil in this polymer system. Theoretical interpretation of these phenomena has been attempted according to the molecular orbital theory. ${ }^{6}$ At present, however, the results show success only in certain limited cases.

With this background, we have attempted to determine these conformational energies from the NMR studies on the corresponding monomer model compound. Our approach is essentially the same as that proposed by Gutowsky, ${ }^{7}$ who estimated conformational energies from the observed temperature dependence of the coupling constants for various 1,2-disubstituted ethanes. Along this line, variation of the couplings in the ${ }^{13} \mathrm{CH}$ satellite side bands of POE and 1,2-dimethoxyethane (DME) has been first analyzed by Connor and McLauchlan. ${ }^{8}$ From the observed temperature dependence of $\mathrm{N}={ }^{3} J_{\mathrm{HH}}+{ }^{3} J_{\mathrm{HH}}^{\prime}$ (i.e., the sum of the two rotationally averaged coupling constants), they concluded that the gauche form is more stable than the trans around the $\mathrm{C}-\mathrm{C}$ bond. The rotational isomeric state (RIS) scheme for the skeletal $\mathrm{C}-\mathrm{C}$ bond is shown in Figure 1(a), where definitions of the trans and gauche couplings are also included. The coupling constants ${ }^{3} J_{\mathrm{HH}}$ and ${ }^{3} J_{\mathrm{HH}}^{\prime}$, being obtainable from a given spectrum, are usually taken to be rotational averages such as

$$
\begin{aligned}
{ }^{3} J_{\mathrm{HH}} & ={ }^{3} J_{\mathrm{AB}}={ }^{3} J_{\mathrm{A}^{\prime} \mathrm{B}^{\prime}} \\
& =J_{\mathrm{G}} f_{t}^{\mathrm{CC}}+(1 / 2)\left(J_{\mathrm{T}}^{\prime}+J_{\mathrm{G}}^{\prime}\right) f_{g}^{\mathrm{CC}}
\end{aligned}
$$

and

$$
\begin{aligned}
{ }^{3} J_{\mathrm{HH}}^{\prime} & ={ }^{3} J_{\mathrm{AB}^{\prime}}={ }^{3} J_{\mathrm{A}^{\prime} \mathrm{B}} \\
& =J_{\mathrm{T}} f_{t}^{\mathrm{CC}},+J_{\mathrm{G}}^{\prime} f_{g}^{\mathrm{CC}}
\end{aligned}
$$

where $f_{t}^{\mathrm{CC}}$ and $f_{g}^{\mathrm{CC}}$ are fractions of the trans and gauche conformers, respectively.

Later, Matsuzaki, and Ito ${ }^{9}$ studied the ${ }^{13} \mathrm{CH}$ satellite side bands of POE and DME by using a spectrometer with a higher resolution. From the $N$ is. $L\left(={ }^{3} J_{\mathrm{HH}}-{ }^{3} J_{\mathrm{HH}}^{\prime}\right)$ plot, they proposed a linear relation between these two quantities: $N=-a L+b, a$ and $b$ being invariant with the solvent and temperature. The best-fit values of the trans and gauche couplings were chosen as follows: $J_{\mathrm{T}}=21.1, J_{\mathrm{G}}=1.8$, $J_{\mathrm{G}}^{\prime}=-1.5$, and $J^{\prime}{ }_{\mathrm{T}}+J_{\mathrm{G}}^{\prime \prime}=14.6$, all units being $\mathrm{Hz}$. The energy differences between the gauche and trans states estimated therefrom are in a range from -0.25 to $-0.5 \mathrm{kcal} \mathrm{mol}^{-1}$ : the value changes somewhat with polarity of the media. On the other hand, Viti et al. ${ }^{10}$ investigated the same conformational equilibrium by the Abraham method. ${ }^{11}$ Use of the trans and gauche coupling constants $\left(J_{\mathrm{T}}=\right.$ 11.91, $J_{\mathrm{G}}=5.76, J_{\mathrm{G}}^{\prime}=2.36$, and $J_{\mathrm{T}}^{\prime}+J_{\mathrm{G}}^{\prime \prime}=$ $12.71 \mathrm{~Hz}$ ) estimated from the electronegativity (3.5) of the methoxyl group gave the energy differences ranging from -0.5 to $-0.8 \mathrm{kcal}$ $\mathrm{mol}^{-1}$. Although the approaches are quite 
different between Matsuzaki's and Viti's group, both assume that the values selected for the trans and gauche couplings are constant, in their fitting procedure, regardless of the solvent and temperature. As is cited above, however, the numerical assignments of $J_{\mathrm{T}}$ 's and $J_{\mathrm{G}}$ 's are very much different from each other. There is an apparent inconsistency between these two research groups. The consequence of such a discrepancy will be discussed in a later section.

In this paper, we report the results of our studies on DME and POE. In addition to the analysis of ${ }^{3} J_{\mathrm{HH}}$ and ${ }^{3} J_{\mathrm{HH}}^{\prime}$ for the $\mathrm{C}-\mathrm{C}$ bond, we also examined the temperature dependence of the vicinal coupling constant ${ }^{3} J_{\mathrm{CH}}$ for the moiety ${ }^{13} \mathrm{CH}_{2}-\mathrm{O}-\mathrm{C}-{ }^{1} \mathrm{H}$. The coupling under consideration carries information about the rotational isomerization around the $\mathrm{C}-\mathrm{O}$ bond: ${ }^{3} J_{\mathrm{CH}}$ may be expressed as a rotational average of the trans and gauche coupling constants (see Figure 1(b)) such as

$$
{ }^{3} J_{\mathrm{CH}}=J_{\mathrm{G}} f_{t}^{\mathrm{CO}}+(1 / 2)\left(J_{\mathrm{T}}+J_{\mathrm{G}}^{\prime}\right) f_{g}^{\mathrm{CO}}
$$

where $f_{t}^{\mathrm{CO}}$ and $f_{g}^{\mathrm{CO}}$ denote fractions of the trans and gauche conformers for the $\mathrm{C}-\mathrm{O}$ bond. Following Connor, ${ }^{8}$ the neighbor-dependent character of the bond rotation along the chain has been taken into account rigorously within the RIS scheme.

The conformational energies for the $\mathrm{C}-\mathrm{C}$ and $\mathrm{C}-\mathrm{O}$ bonds established in this paper may be used in the calculation of conformational properties of the POE chain such as unperturbed dimensions and dipole moments. This will be the subject of the forthcoming paper. ${ }^{12}$

\section{EXPERIMENTAL}

Reagent grade samples of DME and POE $(\mathrm{MW}=4,000)$ are commercially available and were used without further purification. Deuterated solvents such as cyclohexane- $d_{12}$ $\left(c-\mathrm{C}_{6} \mathrm{D}_{12}\right), \quad$ 1,4-dioxane- $d_{8} \quad\left(\left(\mathrm{CD}_{2} \mathrm{CD}_{2} \mathrm{O}\right)_{2}\right)$, chloroform-d $\left(\mathrm{CDCl}_{3}\right), \quad$ methanol- $d_{4}$ $\left(\mathrm{CD}_{3} \mathrm{OD}\right)$, dimethyl- $d_{6}$ sulfoxide $\left(\left(\mathrm{CD}_{3}\right)_{2} \mathrm{SO}\right)$, and heavy water $\left(\mathrm{D}_{2} \mathrm{O}\right)$ were purchased from Merck Sharp \& Dohme Co.

The ${ }^{13} \mathrm{CH}$ satellite side band spectra were recorded on a JEOL-FX-100 spectrometer equipped with a FT system operating at 100 MHz. The FT spectra contain 8192 data points for $300 \mathrm{~Hz}$ spectral width. In the measurements, about 100 transients were accumulated with a $90^{\circ} \mathrm{rf}$ pulse of $14 \mu \mathrm{s} \mathrm{du}$ ration. The pulse repetition time was $10 \mathrm{~s}$. NMR sample tubes with a diameter of $5 \mathrm{~mm}$ were used.

The ${ }^{13} \mathrm{C}$ natural abundance undecoupled NMR spectra were recorded on the same spectrometer operating at $25.15 \mathrm{MHz}$. The FT spectra contain 8192 data points for $500 \mathrm{~Hz}$ spectral width: 300 to 500 transients were accumulated with a $90^{\circ} \mathrm{rf}$ pulse of $20 \mu \mathrm{s} \mathrm{du}-$ ration, the pulse repetition time being $10 \mathrm{~s}$. NMR sample tubes with $10 \mathrm{~mm}$ diameter were used. The temperatures were maintained within $\pm 1^{\circ} \mathrm{C}$ during the NMR measurements.

\section{EXPERIMENTAL RESULTS}

Typical examples of the ${ }^{13} \mathrm{CH}$ satellite side band spectra of DME and POE are shown in Figure 2. These spectra were analyzed by assuming an $\mathrm{AA}^{\prime} \mathrm{BB}^{\prime} \mathrm{X}$ spin system for the moiety $\mathrm{OCH}_{2}-\mathrm{CH}_{2} \mathrm{O}$. Separations between the peaks as indicated by $N$ and $L$ in the figure vary with polarity of the media: as the dielectric constant of the solvent increases, $N$ becomes larger while $L$ tends to be smaller. Also shown in the figure are the stick spectra calculated by the LAOCOON 3 program. The probable errors of the calculated coupling constants, as determined by comparison with the observed spectra, were less than $0.05 \mathrm{~Hz}$. The vicinal ${ }^{1} \mathrm{H}-{ }^{1} \mathrm{H}$ couplings, ${ }^{3} J_{\mathrm{HH}}$ and ${ }^{3} J_{\mathrm{HH}}$, thus determined are summarized in Table I.

Proton-coupled ${ }^{13} \mathrm{C}$ spectra were obtained by gated decoupling. Examples of the spectra for DME and POE are shown in Figure 3. The methoxyl carbon of DME gave a quartet due to couplings with the directly-bonded protons, 
(a)

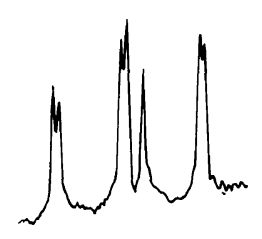

(b)
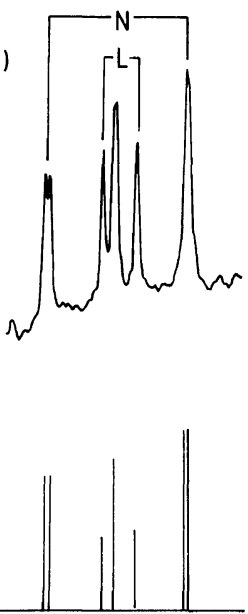

(c)
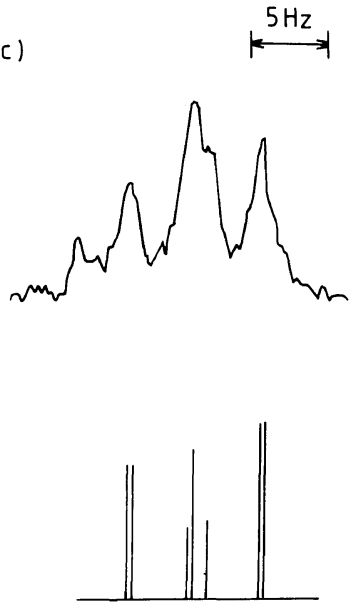

Figure 2. Typical examples of the ${ }^{13} \mathrm{CH}$ satellite side band spectrum. (a) DME in $c-\mathrm{C}_{6} \mathrm{D}_{12}$, (b) DME in $\left(\mathrm{CD}_{3}\right)_{2} \mathrm{SO}$, and (c) POE in $\left(\mathrm{CD}_{2} \mathrm{CD}_{2} \mathrm{O}\right)_{2}$, all taken at $80 \mathrm{C}$. Also shown are the stick spectra calculated by the LAOCOON 3 program.

while the methylene carbon in POE yielded a triplet. As inspection of the spectra for DME should reveal, each peak of the quartet bears a triplet due to vicinal couplings with methylene protons. The values of the vicinal ${ }^{13} \mathrm{CH}_{3}-\mathrm{O}$ $\mathrm{C}-{ }^{1} \mathrm{H}$ couplings in DME could be determined directly from the spectra. For POE, each peak of the triplet exhibits a somewhat more complicated pattern arising from geminal couplings with the adjacent methylene protons as well as vicinal couplings with the methylene protons separated by an oxygen atom. To be accurate, long-range couplings with methylene protons of four bond apart also need to be considered. The vicinal ${ }^{13} \mathrm{CH}_{2}-\mathrm{O}-\mathrm{C}-{ }^{1} \mathrm{H}$ coupling constants in POE were, therefore, determined with the aid of computer program LAOCOON 3. The spin system was taken to be $A_{2} B_{2} C_{2} D_{2} X$. For the example shown in Figure 3(c), the calculated spectrum is illustrated for comparison. The values of ${ }^{3} J_{\mathrm{CH}}$ obtained in this manner are listed in Table II.

As is usually assumed in the Gutowsky treatment, ${ }^{7}$ values of $J_{\mathrm{T}}$ 's and $J_{\mathrm{G}}$ 's may be taken to be invariant over a wide range of temperature. Determination of $f_{g}^{\mathrm{CC}}\left(=1-f_{t}^{\mathrm{CC}}\right)$ and $f_{g}^{\mathrm{CO}}\left(=1-f_{t}^{\mathrm{CO}}\right)$ from eq $1-3$ should be straightforward provided that reliable values of the trans and gauche couplings are available. However, this should not be the case for the present compounds: values of $J_{\mathrm{T}}$ 's and $J_{\mathrm{G}}$ 's reported in the literatures are divergent. In this work, we start with the conformational analysis of the molecular system.

\section{CONFORMATIONAL ENERGY CALCULATION}

In the RIS approximation, the statistical weight matrices for the internal bonds of the POE chain $\left.\mathrm{CH}_{3} \mathrm{fOCH}_{2} \mathrm{CH}_{2}\right]_{n} \mathrm{OCH}_{3}$ is customarily expressed as ${ }^{1.4 .5}$

$$
\begin{aligned}
& \boldsymbol{U}_{2}=\left[\begin{array}{lll}
1 & \rho & \rho
\end{array}\right] \\
& \boldsymbol{U}_{\mathrm{CC}}=\left[\begin{array}{lll}
1 & \sigma & \sigma \\
1 & \sigma & \sigma \omega \\
1 & \sigma \omega & \sigma
\end{array}\right] \\
& \boldsymbol{U}_{\mathrm{CO}}=\left[\begin{array}{lll}
1 & \rho & \rho \\
1 & \rho & \rho \omega \\
1 & \rho \omega & \rho
\end{array}\right]
\end{aligned}
$$


Conformation of 1,2-Dimethoxyethane and Poly(oxyethylene)

Table 1. Experimental values of ${ }^{3} J_{\mathrm{HH}} / \mathrm{Hz}$ and ${ }^{3} J_{\mathrm{HH}}^{\prime} / \mathrm{Hz}$ for $\mathrm{DME}$ and POE, observed in solvents as indicated ${ }^{\mathrm{a}}$

(a) DME

\begin{tabular}{|c|c|c|c|c|c|c|c|c|c|c|c|c|}
\hline \multirow{2}{*}{$\frac{\text { Temp }}{{ }_{\mathrm{C}}}$} & \multicolumn{2}{|c|}{$c-\mathrm{C}_{6} \mathrm{D}_{12}$} & \multicolumn{2}{|c|}{$\left(\mathrm{CD}_{2} \mathrm{CD}_{2} \mathrm{O}\right)_{2}$} & \multicolumn{2}{|c|}{$\mathrm{CDCl}_{3}$} & \multicolumn{2}{|c|}{$\mathrm{CD}_{3} \mathrm{OD}$} & \multicolumn{2}{|c|}{$\left(\mathrm{CD}_{3}\right)_{2} \mathrm{SO}$} & \multicolumn{2}{|c|}{$\mathrm{D}_{2} \mathrm{O}$} \\
\hline & ${ }^{3} J_{\mathrm{HH}}$ & ${ }^{3} J_{\mathrm{HH}}^{\prime}$ & ${ }^{3} J_{\mathrm{HH}}$ & ${ }^{3} J_{\mathrm{HH}}^{\prime}$ & ${ }^{3} J_{\mathrm{HH}}$ & ${ }^{3} J_{\mathrm{HH}}^{\prime}$ & ${ }^{3} J_{\mathrm{HH}}$ & ${ }^{3} J_{\mathrm{HH}}^{\prime}$ & ${ }^{3} J_{\mathrm{HH}}$ & ${ }^{3} J_{\mathrm{HH}}^{\prime}$ & ${ }^{3} J_{\mathrm{HH}}$ & ${ }^{3} J_{\mathrm{HH}}^{\prime}$ \\
\hline 20.0 & & & & & & & 6.32 & 3.02 & & & & \\
\hline 28.0 & 6.01 & 4.25 & & & 6.30 & 3.15 & & & 6.20 & 3.49 & & \\
\hline 31.0 & & & & & & & & & & & 6.50 & 2.71 \\
\hline 40.0 & 6.01 & 4.32 & 6.03 & 4.25 & 6.26 & 3.19 & 6.24 & 3.19 & 6.17 & 3.54 & 6.46 & 2.79 \\
\hline 50.0 & 5.96 & 4.35 & 5.99 & 4.30 & 6.23 & 3.30 & 6.17 & 3.28 & 6.14 & 3.58 & 6.43 & 2.85 \\
\hline 60.0 & 5.96 & 4.36 & 5.98 & 4.32 & 6.19 & 3.41 & 6.18 & 3.33 & 6.12 & 3.63 & & \\
\hline 70.0 & 5.95 & 4.41 & 5.97 & 4.38 & 6.12 & 3.55 & 6.14 & 3.39 & 6.12 & 3.70 & 6.35 & 3.05 \\
\hline 80.0 & & & 5.96 & 4.42 & 6.06 & 3.64 & 6.07 & 3.46 & 6.10 & 3.75 & 6.35 & 3.10 \\
\hline 90.0 & 5.93 & 4.47 & 5.94 & 4.44 & 6.07 & 3.66 & 6.04 & 3.54 & 6.08 & 3.81 & 6.29 & 3.19 \\
\hline 100.0 & 5.91 & 4.52 & 5.93 & 4.49 & 6.04 & 3.77 & 6.01 & 3.60 & 6.06 & 3.86 & 6.25 & 3.25 \\
\hline 110.0 & & & & & & & & & 6.06 & 3.94 & 6.19 & 3.33 \\
\hline 120.0 & & & & & & & & & 6.04 & 3.99 & 6.12 & 3.41 \\
\hline 130.0 & & & & & & & & & 6.02 & 4.05 & 6.13 & 3.50 \\
\hline 140.0 & & & & & & & & & 6.00 & 4.07 & & \\
\hline
\end{tabular}

(b) POE

\begin{tabular}{|c|c|c|c|c|}
\hline \multirow{2}{*}{$\frac{\text { Temp }}{\mathrm{C}}$} & \multicolumn{2}{|c|}{$\left(\mathrm{CD}_{2} \mathrm{CD}_{2} \mathrm{O}\right)_{2}$} & \multicolumn{2}{|c|}{$\mathrm{D}_{2} \mathrm{O}$} \\
\hline & ${ }^{3} J_{\mathrm{HH}}$ & ${ }^{3} J_{\mathrm{HH}}^{\prime}$ & ${ }^{3} J_{\mathrm{HH}}$ & ${ }^{3} J_{\mathrm{HH}}^{\prime}$ \\
\hline 25.0 & & & 6.29 & 2.52 \\
\hline 40.0 & 6.10 & 4.10 & 6.28 & 2.62 \\
\hline 50.0 & 6.07 & 4.20 & 6.21 & 2.74 \\
\hline 60.0 & 6.05 & 4.25 & 6.17 & 2.82 \\
\hline 70.0 & 6.04 & 4.29 & 6.18 & 2.90 \\
\hline 80.0 & 5.99 & 4.35 & 6.14 & 2.97 \\
\hline 90.0 & 6.01 & 4.37 & & \\
\hline 100.0 & 5.98 & 4.47 & & \\
\hline
\end{tabular}

a Concentrations of the sample are $5 \%(\mathrm{v} / \mathrm{v})$ for DME and $5 \%(\mathrm{w} / \mathrm{v})$ for POE.

$$
\boldsymbol{U}_{\mathrm{OC}}=\left[\begin{array}{lll}
1 & \rho & \rho \\
1 & \rho & 0 \\
1 & 0 & \rho
\end{array}\right]
$$

Here $\boldsymbol{U}_{2}$ is applicable to the second bond of the chain and given in the row form. Subscripts $\mathrm{CC}, \mathrm{CO}$, and OC specify the bond to which each matrix should be applied. The statistical weight parameters $\rho$ and $\sigma$ were assigned to the first-order interaction defined for the $\mathrm{C}-\mathrm{O}$ and $\mathrm{C}-\mathrm{C}$ bonds, respectively, the weight of unity being assigned to the trans state. ${ }^{13}$ The secondorder interaction taking place by a $g^{ \pm} g^{\mp}$ (or $g^{\mp} g^{ \pm}$) rotation about the two consecutive $\mathrm{C}-\mathrm{O}$ and $\mathrm{C}-\mathrm{C}$ bonds is designated with $\omega$. An energy contour diagram obtained for the rotation around the $\mathrm{C}-\mathrm{O}$ and $\mathrm{C}-\mathrm{C}$ bonds of DME is shown in Figure 4. The potential energy functions required in these calculations were mostly taken from the previous paper. ${ }^{1}$ To take account of the observed gauche preference over the trans state, the torsional potential energy function of the $\mathrm{C}-\mathrm{C}$ bond was modi- 


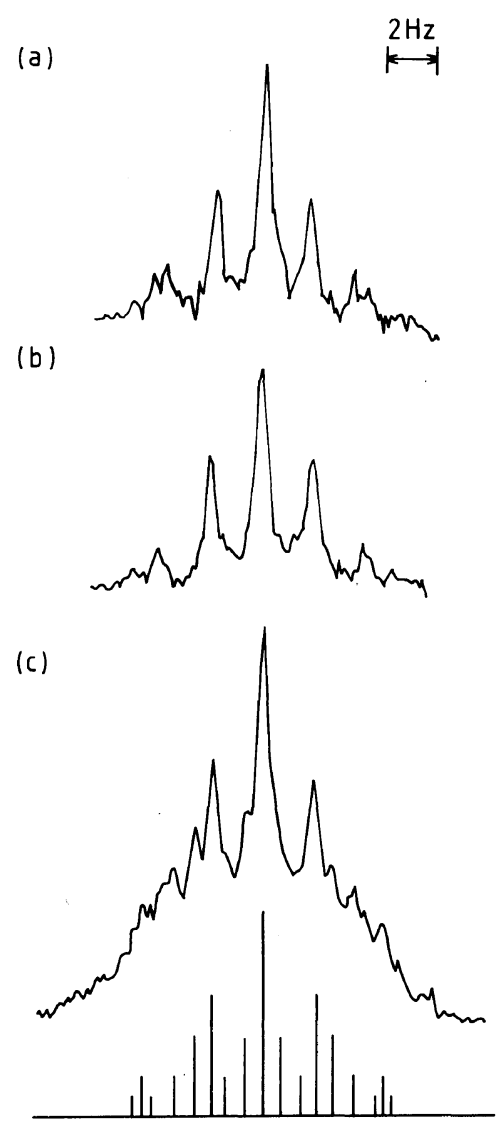

Figure 3. Proton-coupled ${ }^{13} \mathrm{C}$ spectra of (a) DME in $c$ $\mathrm{C}_{6} \mathrm{D}_{12}$, (b) $\mathrm{DME}$ in $\left(\mathrm{CD}_{3}\right)_{2} \mathrm{SO}$, and (c) POE in $\left(\mathrm{CD}_{2} \mathrm{CD}_{2} \mathrm{O}\right)_{2}$, all taken at $80^{\circ} \mathrm{C}$. The calculated stick spectrum is also illustrated for POE.

fied by inclusion of an extra stabilization term $\Delta E$ : Thus,

$$
\begin{aligned}
E_{\mathrm{tor}}\left(\phi_{\mathrm{CC}}\right)= & \left(E_{0} / 2\right)\left(1-\cos 3 \phi_{\mathrm{CC}}\right) \\
& -(\Delta E / 2)\left(1+\cos 3 \phi_{\mathrm{CC}}\right)
\end{aligned}
$$

where $\Delta E$ is the correction term for the gauche oxygen effect ${ }^{14}$ defined as $\Delta E=0$ for $-60^{\circ} \leq$ $\phi_{\mathrm{CC}} \leq 60^{\circ}$ and $\Delta E=0.95 \mathrm{kcal} \mathrm{mol}^{-1}$ for $60^{\circ}<$ $\phi_{\mathrm{CC}}<300^{\circ}$. The height of the torsional barrier located on both sides of the trans state $\left(E_{0}\right)$ was taken to be $2.8 \mathrm{kcal} \mathrm{mol}^{-1}$. This expression, when used in combination with the equations introduced previously ${ }^{1}$ for the nonbonded van der Waals and Coulombic interactions, leads to a value of $E\left(0^{\circ}, 120^{\circ}\right)=-0.4 \mathrm{kcal}$ $\mathrm{mol}^{-1}$ for the gauche minimum as expressed relative to the trans state ( $c f$. Figure 4).

Following the procedure developed by Suter and Flory, ${ }^{16}$ the conformational partition functions $z$, average energies $\langle E\rangle$, and averaged rotation angles $\langle\phi\rangle$ were estimated for the five nonequivalent states. The regions associated with the individual states are indicated by squares in Figure 4. Calculations were carried out for the energies $E\left(\phi_{\mathrm{CO}}, \phi_{\mathrm{CC}}\right)$ taken at $10^{\circ}$ intervals: all regions for which $E \leq 3$ $\mathrm{kcal} \mathrm{mol}^{-1}$ relative to the $t t$ minimum are included. The results are summarized in Table III. Statistical weight parameters may be in general defined as

$$
\eta=\eta_{0} \exp \left(-E_{\eta} / R T\right)
$$

where $\eta$ represents any one of the statistical weights $\rho, \sigma$ and $\omega$, and $T$ is the temperature. The preexponential factor $\eta_{0}$ and the average energy $E_{\eta}$ can be deduced ${ }^{16}$ from the $z$ and $\langle E\rangle$ values given in Table III. The results are listed in Table IV. It should be noted here that $\rho_{0}$ departs significantly from unity. The consequence of this departure will be discussed when the conformational properties of the polymer chain is treated in the forthcoming paper. $^{12}$

With the statistical weight parameters thus evaluated, the fraction of conformers may be calculated for given bonds of the chain. For DME, analytical expressions such as shown below can be obtained by some simple manipulation:

$$
\begin{aligned}
f_{g}^{\mathrm{CC}} & =1-f_{t}^{\mathrm{CC}} \\
& =p \sigma /(1+p \sigma)
\end{aligned}
$$

where

$$
p=2\{(1+\rho+\rho \omega) /(1+2 \rho)\}^{2}
$$

and

$$
\begin{aligned}
f_{g}^{\mathrm{CO}} & =1-f_{t}^{\mathrm{CO}} \\
& =q \rho /(1+q \rho)
\end{aligned}
$$


Conformation of 1,2-Dimethoxyethane and Poly(oxyethylene)

Table II. Experimental values of ${ }^{3} J_{\mathrm{CH}} / \mathrm{Hz}$ for DME and POE, observed in solvents as indicated ${ }^{\mathrm{a}}$

(a) DME

\begin{tabular}{|c|c|c|c|c|c|c|c|c|c|c|c|}
\hline \multicolumn{2}{|c|}{$c-\mathrm{C}_{6} \mathrm{D}_{12}$} & \multicolumn{2}{|c|}{$\left(\mathrm{CD}_{2} \mathrm{CD}_{2} \mathrm{O}\right)_{2}$} & \multicolumn{2}{|c|}{$\mathrm{CDCl}_{3}$} & \multicolumn{2}{|c|}{$\mathrm{CD}_{3} \mathrm{OD}$} & \multicolumn{2}{|c|}{$\left(\mathrm{CD}_{3}\right)_{2} \mathrm{SO}$} & \multicolumn{2}{|c|}{$\mathrm{D}_{2} \mathrm{O}$} \\
\hline Temp $/{ }^{\circ} \mathrm{C}$ & ${ }^{3} J_{\mathrm{CH}}$ & Temp $/{ }^{\circ} \mathrm{C}$ & ${ }^{3} J_{\mathrm{CH}}$ & Temp $/{ }^{\circ} \mathrm{C}$ & ${ }^{3} J_{\mathrm{CH}}$ & Temp $/{ }^{\circ} \mathrm{C}$ & ${ }^{3} J_{\mathrm{CH}}$ & Temp $/{ }^{\circ} \mathrm{C}$ & ${ }^{3} J_{\mathrm{CH}}$ & Temp $/{ }^{\circ} \mathrm{C}$ & ${ }^{3} J_{\mathrm{CH}}$ \\
\hline 40.0 & 1.89 & 40.0 & 1.87 & 40.0 & 1.68 & 40.0 & 1.87 & 24.8 & 1.75 & 24.8 & 1.62 \\
\hline 50.0 & 1.89 & 50.0 & 1.87 & 50.0 & 1.70 & 50.0 & 1.88 & 41.6 & 1.85 & 37.5 & 1.66 \\
\hline 60.0 & 1.92 & 60.0 & 1.93 & 60.0 & 1.73 & 60.0 & 1.90 & 58.8 & 1.92 & 50.7 & 1.67 \\
\hline 70.0 & 1.94 & 70.0 & 1.93 & 70.0 & 1.74 & 70.0 & 1.93 & 71.3 & 1.89 & 68.5 & 1.76 \\
\hline 80.0 & 1.97 & 80.0 & 1.92 & 80.0 & 1.83 & 80.0 & 1.95 & 92.7 & 1.94 & 85.5 & 1.81 \\
\hline 90.0 & 1.99 & 90.0 & 1.99 & 90.0 & 1.85 & & & 117.0 & 2.10 & 102.0 & 1.92 \\
\hline 100.0 & 2.01 & & & 100.0 & 1.86 & & & & & & \\
\hline
\end{tabular}

(b) POE

\begin{tabular}{|c|c|c|c|}
\hline \multicolumn{2}{|c|}{$\left(\mathrm{CD}_{2} \mathrm{CD}_{2} \mathrm{O}\right)_{2}$} & \multicolumn{2}{|c|}{$\mathrm{D}_{2} \mathrm{O}$} \\
\hline $\mathrm{Temp} /{ }^{\circ} \mathrm{C}$ & ${ }^{3} J_{\mathrm{CH}}$ & Temp $/{ }^{\circ} \mathrm{C}$ & ${ }^{3} J_{\mathrm{CH}}$ \\
\hline 20.0 & 1.83 & 40.5 & 1.61 \\
\hline 40.0 & 1.87 & 57.9 & 1.66 \\
\hline 50.0 & 1.87 & 70.1 & 1.73 \\
\hline 60.0 & 1.93 & 81.3 & 1.68 \\
\hline 70.0 & 1.93 & 92.0 & 1.83 \\
\hline 80.0 & 1.92 & & \\
\hline 90.0 & 1.99 & & \\
\hline
\end{tabular}

a Concentrations of the sample are $30 \%(\mathrm{v} / \mathrm{v})$ for DME and $30 \%(\mathrm{w} / \mathrm{v})$ for POE.

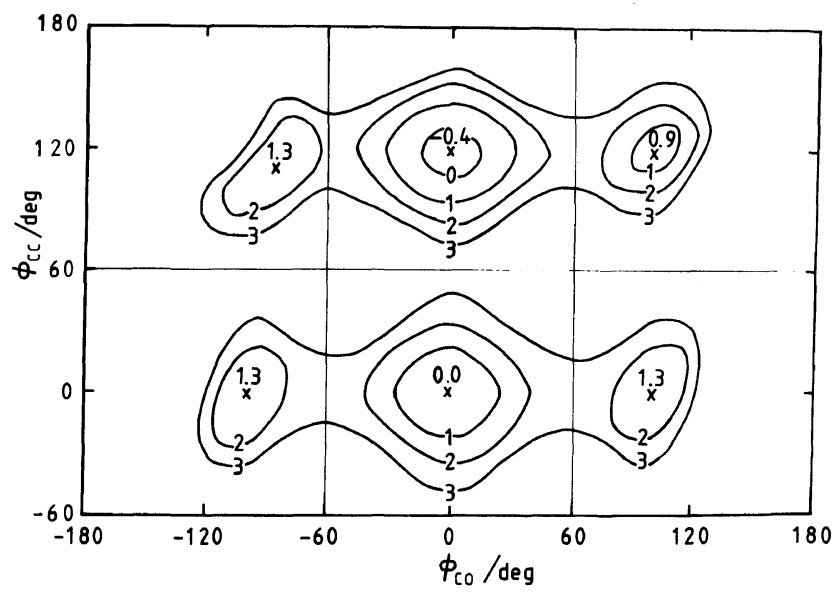

Figure 4. Potential energy contours for bond pair C-O, C-C of DME, expressed in $\mathrm{kcal} \mathrm{mol}^{-1}$ relative to the trans-trans $(0,0)$ minimum. The $\mathrm{X}$ denotes local minima. The diagram for the range $-180^{\circ} \leq \phi_{\mathrm{CC}} \leq-60^{\circ}$ may be generated by inversion through the origin $(0,0)$. 
Table III. Partition functions, average energies, and averaged rotational angles estimated from the potential energy contour map for the temperature of $25^{\circ} \mathrm{C}$

\begin{tabular}{lccccr}
\hline \multirow{2}{*}{$\begin{array}{c}\text { Rotational } \\
\text { state }\end{array}$} & $z$ & $\frac{\langle E\rangle}{}$ & & $\left\langle\phi_{\mathrm{oc}}\right\rangle,\left\langle\phi_{\mathrm{cc}}\right\rangle$ \\
\cline { 5 - 6 } \cline { 5 - 6 } & & $\mathrm{kcal} \mathrm{mol}^{-1}$ & & \multicolumn{2}{c}{$\mathrm{deg}$} \\
\hline$t$ & 1.00 & 0.61 & & 0.0, & 0.0 \\
$t g^{ \pm}$ & 1.88 & 0.23 & & $0.0,117.0$ \\
$g^{ \pm} t$ & 0.09 & 1.72 & & $98.1, \quad 0.0$ \\
$g^{ \pm} g^{ \pm}$ & 0.18 & 1.33 & & $98.1,117.0$ \\
$g^{\mp} g^{ \pm}$ & 0.06 & 1.87 & & $-85.0,110.6$ \\
\hline
\end{tabular}

Table IV. Parameters for the statistical weight factor deduced from energy calculations

\begin{tabular}{cccccccc}
\hline$\frac{E_{\sigma}}{\mathrm{kcal} \mathrm{mol}^{-1}}$ & & $E_{\rho}$ & & $E_{\omega}$ & & & \\
${\mathrm{mol}^{-1}} }$ & $\frac{\mathrm{kcal} \mathrm{mol}^{-1}}{\mathrm{kcal}_{0}}$ & & $\rho_{0}$ & $\omega_{0}$ \\
\hline-0.38 & 1.11 & 0.53 & 0.99 & 0.61 & 0.88 \\
\hline
\end{tabular}

where

$$
\begin{gathered}
q=2\left\{1+\sigma(1+\omega)+\rho\left(2+\sigma+2 \sigma \omega+\sigma \omega^{2}\right)\right\} / \\
\{1+2 \sigma(1+\rho \omega)+2 \rho(1+\sigma)\}
\end{gathered}
$$

Fractions were calculated to be $f_{g}^{\mathrm{CC}}=0.78$ and $f_{g}^{\mathrm{CO}}=0.12$ for the temperature of $25^{\circ} \mathrm{C}$. For an infinitely long POE chain, the bond conformation can be easily calculated by the eigenvalue method. ${ }^{5}$

$$
\begin{gathered}
f_{\mathrm{g}}^{\mathrm{CC}}=\partial \ln \lambda / \partial \ln \sigma \\
f_{g}^{\mathrm{CO}}=(1 / 2) \partial \ln \lambda / \partial \ln \rho
\end{gathered}
$$

where $\lambda$ is the largest eigen-value of the statistical weight matrix defined for the repeat unit, i.e.,

$$
\boldsymbol{U}=\boldsymbol{U}_{\mathrm{CC}} \boldsymbol{U}_{\mathrm{CO}} \boldsymbol{U}_{\mathrm{OC}}
$$

Here $\boldsymbol{U}_{\mathrm{CC}}, \boldsymbol{U}_{\mathrm{CO}}$, and $\boldsymbol{U}_{\mathrm{OC}}$ are given in eq $5-7$. The values of $f_{g}^{\mathrm{CC}}$ and $f_{g}^{\mathrm{CO}}$ were found to be the same as those for DME.

\section{ESTIMATION OF CONFORMATIONAL ENERGIES FROM THE NMR DATA}

As is manifestly shown in the expression given in eq 10 and 11 , the temperature dependence of $f_{g}^{\mathrm{CC}}$ largely arises from factor $\sigma$ in DME. Contributions from $\rho$ and $\omega$ emerge through factor $p$, and thus should be minor. Since the trans and gauche coupling constants are assumed to be invariant with temperature, the thermal variation of ${ }^{3} J_{\mathrm{HH}}$ and ${ }^{3} J_{\mathrm{HH}}^{\prime}$, as expressed in eq 1 and 2, should solely take place through the fraction term $f_{g}^{\mathrm{CC}}(=1-$ $f_{t}^{\mathrm{CC}}$ ). Similarly, $\rho$ is the major factor responsible for the temperature dependence of $f_{g}^{\mathrm{CO}}$ $\left(=1-f_{t}^{\mathrm{CO}}\right.$ ) (cf. eq 12 and 13), and therefore, for that of ${ }^{3} J_{\mathrm{CH}}$ (cf. eq 3 ).

For POE, the correlation among the individual statistical weight parameters is implicit in the expression given by eq 14 and 15. Nevertheless, essentially the same treatment is applicable to the polymer chain: i.e., eq 14 and 15 can be used in place of eq 10 and 12 , respectively (see seq.).

To elucidate conformational energies from the NMR measurements, we adopt following express-ions for the statistical weight parameters

$$
\begin{aligned}
& \sigma=0.99 \exp \left(-E_{\sigma} / R T\right) \\
& \rho=0.61 \exp \left(-E_{\rho} / R T\right) \\
& \omega=0.88 \exp \left(-E_{\omega} / R T\right)
\end{aligned}
$$

where numerical values of the preexponential factors are those estimated by the energy calculation, and taken from Table IV. The effect arising from the difference in the shape of the potential well (Figure 4) is thus taken into account. In this section, we treat $E_{\sigma}$ and $E_{\rho}$ as unknown parameters, instead of adopting the numerical results previously calculated. We estimate the magnitude of $E_{\sigma}$ from the analysis of the experimental values of ${ }^{3} J_{\mathrm{HH}}$ and ${ }^{3} J_{\mathrm{HH}}^{\prime}$. A probable range of $E_{\rho}$ is similarly deduced from the study on ${ }^{3} J_{\mathrm{CH}}$. In the following treatment, a value of $E_{\omega}=0.53 \mathrm{kcal} \mathrm{mol}^{-1}$ is 
used as calculated (Table IV).

Analysis of the ${ }^{3} J_{\mathrm{HH}}$ and ${ }^{3} \mathrm{~J}^{\prime}{ }_{\mathrm{HH}}$ Data

According to the expression given in eq 1, 10 , and 11, vicinal coupling constant ${ }^{3} J_{\mathrm{HH}}$ may be treated as a function of $J_{\mathrm{G}}, J_{\mathrm{T}}^{\prime}+J_{\mathrm{G}}^{\prime \prime}$, and $E_{\sigma}$, factor $P$ being deduced from the calculated values of $E_{\rho}$ and $E_{\omega}$. For chosen values of $E_{\sigma}$, a set of best-fit values of $J_{\mathrm{G}}$ and $J^{\prime}{ }_{\mathrm{T}}+J^{\prime \prime}{ }_{\mathrm{G}}$ were selected by performing the least-squares treatment on the experimental ${ }^{3} J_{\mathrm{HH}}$ data (Table I). ${ }^{17}$ Results for DME measured in $c-\mathrm{C}_{6} \mathrm{D}_{12}$, a typical nonpolar solvent, are shown by the solid curves in Figure 5, where values of $J_{\mathrm{G}}$ and $J_{\mathrm{T}}^{\prime}+J_{\mathrm{G}}^{\prime \prime}$ thus obtained are plotted against $E_{\sigma}$. As the magnitude of $E_{\sigma}$ becomes large, $f_{g}^{\mathrm{CC}}$ approaches unity, and thus the major contribution to ${ }^{3} J_{\mathrm{HH}}$ tends to arise from the $J_{\mathrm{T}}^{\prime}+J_{\mathrm{G}}^{\prime \prime}$ term (cf. eq 1 ). As is seen in this figure, $J_{\mathrm{G}}$ as well as $J_{\mathrm{T}}^{\prime}+J_{\mathrm{G}}^{\prime \prime}$ approach asymptotic values for the range $E_{\sigma}<-0.6 \mathrm{kcal}$ $\mathrm{mol}^{-1}$. A set of values of $J_{\mathrm{T}}$ and $J_{\mathrm{G}}^{\prime}$ deduced similarly from the experimental ${ }^{3} J_{\mathrm{HH}}^{\prime}$ data (in $\left.c-\mathrm{C}_{6} \mathrm{D}_{12}\right)$ are plotted against $E_{\sigma}$. by the broken curves in Figure 5. If we adopt a semiempirical criterion ${ }^{18}$ which dictates $J_{\mathrm{G}} / J_{\mathrm{T}}=0.2$ to 0.4 for the gauche $\left(J_{\mathrm{G}}\right)$ and trans couplings $\left(J_{\mathrm{T}}\right)$ in the moiety ${ }^{1} \mathrm{H}-\mathrm{C}-\mathrm{C}-{ }^{1} \mathrm{H}$, a value of $E_{\sigma}$ larger than $-0.3 \mathrm{kcal} \mathrm{mol}^{-1}$ becomes improbable.

To facilitate the analysis, we introduce an assumption ${ }^{20}$ such that

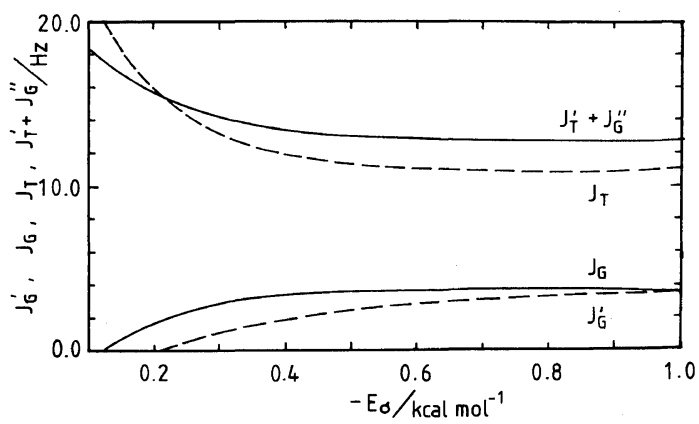

Figure 5. The best-fit values of $J_{\mathrm{T}}, J_{\mathrm{G}}, J_{\mathrm{G}}^{\prime}$, and $J_{\mathrm{T}}^{\prime}+J_{\mathrm{G}}^{\prime \prime}$ plotted against $-E_{\sigma}$ for DME in $c-\mathrm{C}_{6} \mathrm{D}_{12}$. The results for ${ }^{3} J_{\mathrm{HH}}$ are indicated by the solid curves, and those for ${ }^{3} J_{\mathrm{HH}}^{\prime}$ by the broken curves.

$$
J_{\mathrm{T}}=J^{\prime}{ }_{\mathrm{T}}
$$

and

$$
J_{\mathrm{G}}=J_{\mathrm{G}}^{\prime}=J_{\mathrm{G}}^{\prime \prime}
$$

As is seen in Figure 5, the results of the preceding analysis are compatible with these approximations. Introduction of these relations into eq 1 and 2, followed by elimination of $f_{t}^{\mathrm{CC}}$ and $f_{g}^{\mathrm{CC}}$ yields

$$
{ }^{3} J_{\mathrm{HH}}=-(1 / 2)^{3} J_{\mathrm{HH}}^{\prime}+(1 / 2) J_{\mathrm{T}}+J_{\mathrm{G}}
$$

As indicated in Figure 6, the ${ }^{3} J_{\mathrm{HH}}$ vs. ${ }^{3} J_{\mathrm{HH}}^{\prime}$ plot

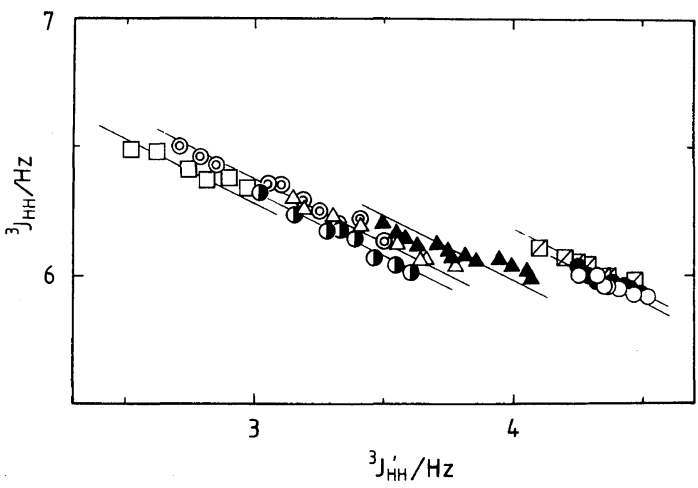

Figure 6. Plot of ${ }^{3} J_{\mathrm{HH}}$ vs. ${ }^{3} J_{\mathrm{HH}}^{\prime}: \mathrm{DME} / c-\mathrm{C}_{6} \mathrm{D}_{12}(\bigcirc)$, $\left(\mathrm{CD}_{2} \mathrm{CD}_{2} \mathrm{O}\right)_{2}(\bigcirc), \mathrm{CDCl}_{3}(\triangle), \mathrm{CD}_{3} \mathrm{OD}(\mathrm{O}),\left(\mathrm{CD}_{3}\right)_{2} \mathrm{SO}$ $(\Delta)$, and $\mathrm{D}_{2} \mathrm{O}(\odot) ; \mathrm{POE} /\left(\mathrm{CD}_{2} \mathrm{CD}_{2} \mathrm{O}\right)_{2}(\square), \mathrm{D}_{2} \mathrm{O}(\square)$. Solid lines with the $-(1 / 2)$ slope are drawn for representative sets of data.

Table V. Values of $(1 / 2) J_{\mathrm{T}}+J_{\mathrm{G}}$ estimated from the temperature dependence of ${ }^{3} J_{\mathrm{HH}}$ and ${ }^{3} J_{\mathrm{HH}}^{\prime}(c f$. Figure 6)

\begin{tabular}{clc}
\hline & & $(1 / 2) J_{\mathrm{T}}+J_{\mathrm{G}}$ \\
\cline { 3 - 3 } & Solvent & $\mathrm{Hz}$ \\
\hline \multirow{7}{*}{ DME } & & \\
& $c-\mathrm{C}_{6} \mathrm{D}_{12}$ & 8.15 \\
& $\left(\mathrm{CD}_{2} \mathrm{CD}_{2} \mathrm{O}\right)_{2}$ & 8.15 \\
& $\mathrm{CDCl}_{3}$ & 7.90 \\
& $\mathrm{CD}_{3} \mathrm{OD}$ & 7.80 \\
& $\left(\mathrm{CD}_{3}\right)_{2} \mathrm{SO}$ & 7.95 \\
\multirow{5}{*}{ POE } & $\mathrm{D}_{2} \mathrm{O}$ & 7.90 \\
& & \\
& $\left(\mathrm{CD}_{2 .} \mathrm{CD}_{2} \mathrm{O}\right)_{2}$ & 8.20 \\
& $\mathrm{D}_{2} \mathrm{O}$ & 7.80 \\
\hline
\end{tabular}


Table VI. Values of $J_{\mathrm{T}}, J_{\mathrm{G}}$, and $E_{\sigma}$ for the $\mathrm{C}-\mathrm{C}$ bond, estimated from the observed ${ }^{3} J_{\mathrm{HH}}$ and ${ }^{3} J_{\mathrm{HH}}^{\prime}$

\begin{tabular}{|c|c|c|c|c|}
\hline & \multirow{2}{*}{ Solvent } & $J_{\mathrm{T}}$ & $J_{\mathrm{G}}$ & $E_{\sigma}$ \\
\hline & & $\mathrm{Hz}$ & $\mathrm{Hz}$ & $\mathrm{kcal} \mathrm{mol}^{-1}$ \\
\hline \multicolumn{5}{|l|}{ DME } \\
\hline & $c-\mathrm{C}_{6} \mathrm{D}_{12}$ & 11.7 & 2.3 & -0.5 \\
\hline & $\left(\mathrm{CD}_{2} \mathrm{CD}_{2} \mathrm{Q}\right)_{2}$ & 11.7 & 2.3 & -0.5 \\
\hline & $\mathrm{CDCl}_{3}$ & 11.2 & 2.3 & -0.9 \\
\hline & $\mathrm{CD}_{3} \mathrm{OD}$ & 11.2 & 2.2 & -0.9 \\
\hline & $\left(\mathrm{CD}_{3}\right)_{2} \mathrm{SO}$ & 11.3 & 2.3 & -0.8 \\
\hline & $\mathrm{D}_{2} \mathrm{O}$ & 11.2 & 2.3 & -1.2 \\
\hline \multicolumn{5}{|l|}{ POE } \\
\hline & $\left(\mathrm{CD}_{2} \mathrm{CD}_{2} \mathrm{O}\right)_{2}$ & 11.8 & 2.3 & -0.5 \\
\hline & $\mathrm{D}_{2} \mathrm{O}$ & 11.2 & 2.2 & -1.2 \\
\hline
\end{tabular}

generally conforms to the -(1/2) slope for given solvent systems. To avoid overlaps, the solid lines of this slope are drawn only for representative sets of data in the figure. Numerical values of the $(1 / 2) J_{\mathrm{T}}+J_{\mathrm{G}}$ term estimated from Figure 6 are listed in Table V. The values tend to lower somewhat from $8.15 \mathrm{~Hz}$ in $c-\mathrm{C}_{6} \mathrm{D}_{12}$ to $7.80 \mathrm{~Hz}$ in $\mathrm{CD}_{3} \mathrm{OD}$. Practically, no difference was found between DME and POE. Use of these $(1 / 2) J_{\mathrm{T}}+J_{\mathrm{G}}$ values allows us to determine $J_{\mathrm{T}}, J_{\mathrm{G}}$, and $E_{\sigma}$, either from eq 1 or 2 , by the least-squares method. In this study, the variance $\delta$ defined below was minimized by an iterative process:

$$
\delta=\sum\left(\Delta^{3} J_{\mathrm{HH}}+\Delta^{3} J_{\mathrm{HH}}^{\prime}\right)
$$

where

$$
\Delta^{3} J_{\mathrm{HH}}={ }^{3} J_{\mathrm{HH}: \text { obsd }}-{ }^{3} J_{\mathrm{HH}: \text { calcd }}
$$

and

$$
\Delta^{3} J_{\mathrm{HH}}^{\prime}={ }^{3} J_{\mathrm{HH} ; \mathrm{obsd}}^{\prime}-{ }^{3} J_{\mathrm{HH}: \text { calcd }}^{\prime}
$$

Here the suffices given to ${ }^{3} J_{\mathrm{HH}}$ and ${ }^{3} J_{\mathrm{HH}}^{\prime}$ indicate whether they were obtained by the experimental observations (Table I) or by calculations with a given set of parameters. The summation was taken over all the data collected at different temperatures. In the neighborhood of the minimum, variation of $\delta$ was plotted against the ratio $J_{\mathrm{G}} / J_{\mathrm{T}}$ as well as

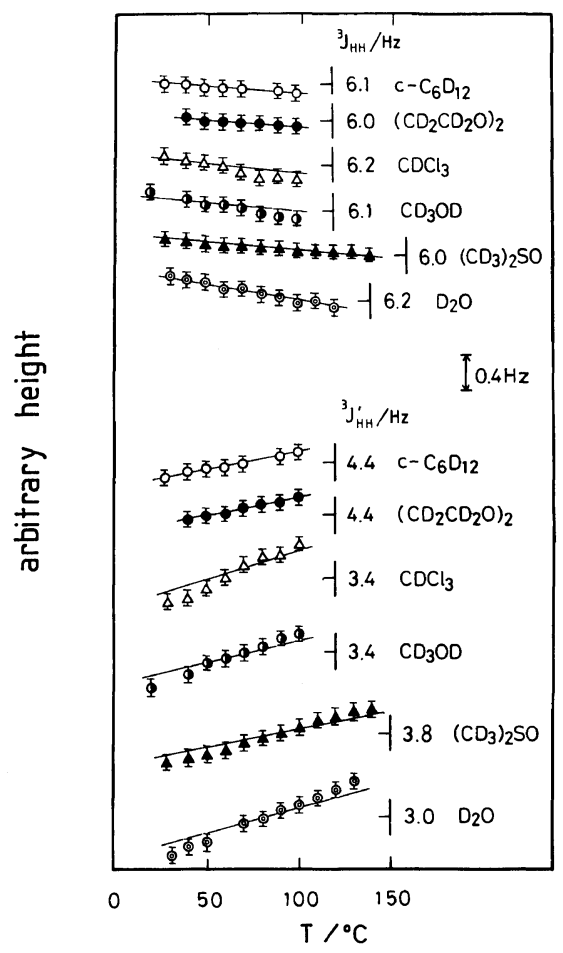

Figure 7. The temperature dependence of ${ }^{3} J_{\mathrm{HH}}$ and ${ }^{3} J_{\mathrm{HH}}^{\prime}$ for DME. The results for ${ }^{3} J_{\mathrm{HH}}$ are shown in the upper section, and those for ${ }^{3} J_{\mathrm{HH}}^{\prime}$ in the lower section. The curves drawn through the experimental points were calculated by using the best-fit values of $J_{\mathrm{T}}, J_{\mathrm{G}}$, and $E_{\sigma}$. The ordinate scales are indicated on the right to the individual curves. The solvents used in experiments are also shown.

$J_{\mathrm{G}}$. The curves derived for $J_{\mathrm{G}} / J_{\mathrm{T}}$ and $J_{\mathrm{G}}$ were all found to be quite flat around the minimum. For selection of a probable set of parameters, we adopted two conventional criterions ${ }^{18.19}$ : $J_{\mathrm{G}} / J_{\mathrm{T}}=0.2$ to 0.4 and $J_{\mathrm{G}}=2$ to $4 \mathrm{~Hz}$. In most cases, the minimum in $\delta$ was displaced slightly from the range of $J_{\mathrm{G}} / J_{\mathrm{T}}$ and/or $J_{\mathrm{G}}$ set forth above. A set of parameters $J_{\mathrm{T}}, J_{\mathrm{G}}$, and $E_{\sigma}$ which gives the minimum in $\delta$ within the requirement for the coupling constants was chosen as the best values (see Table VI). The values of $J_{\mathrm{T}}, J_{\mathrm{G}}$, and $E_{\sigma}$ chosen for POE by the same criterion are also included in the table.

Compatibility of these sets was tested against the experimental data in Figure 7, where values of ${ }^{3} J_{\mathbf{H H}}$ and ${ }^{3} J_{\mathrm{HH}}^{\prime}$ are plotted as a 


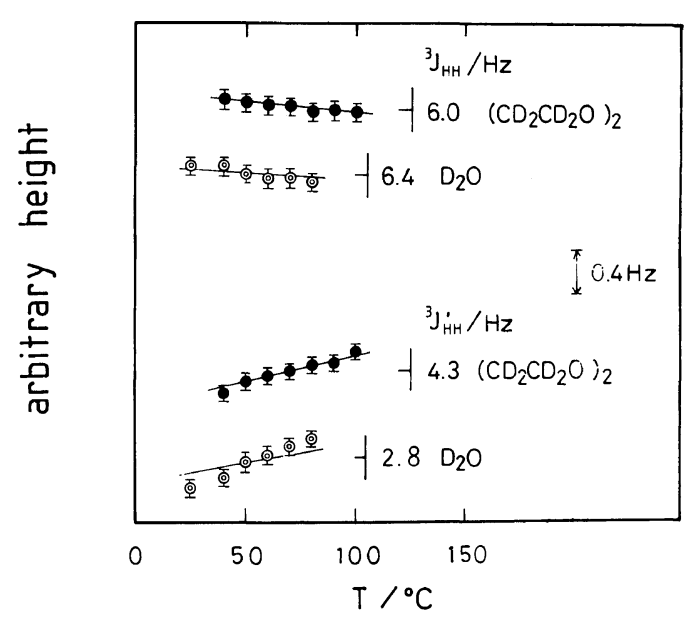

Figure 8. The temperature dependence of ${ }^{3} J_{\mathrm{HH}}$ and ${ }^{3} J_{\mathrm{HH}}^{\prime}$ for POE. See legend to Figure 7.

function of temperature. For a nonpolar solvent such as $c-\mathrm{C}_{6} \mathrm{D}_{12}$ and $\left(\mathrm{CD}_{2} \mathrm{CD}_{2} \mathrm{O}\right)_{2}$, the experimental observations are very well reproduced by the theoretical calculations (solid curves) based on eq 1 and 2 . The values of $E_{\sigma}$ $\left(-0.5 \mathrm{kcal} \mathrm{mol}^{-1}\right)$ estimated from the observed ${ }^{3} J_{\mathrm{HH}}$ and ${ }^{3} J_{\mathrm{HH}}^{\prime}$ in $c-\mathrm{C}_{6} \mathrm{D}_{12}$ are reasonably in accord with the result derived from the conformational energy calculations $(-0.4 \mathrm{kcal}$ $\left.\mathrm{mol}^{-1}\right)$. Small, but somewhat systematic deviations are observed in a solvent such as $\mathrm{CDCl}_{3}, \mathrm{CD}_{3} \mathrm{OD},\left(\mathrm{CD}_{3}\right)_{2} \mathrm{SO}$, and $\mathrm{D}_{2} \mathrm{O}$ ( $c f$. Figure 7). These solvents are highly polar and/or capable of forming hydrogen-bonds. Figure 8 shows a similar comparison for POE. Agreement is very satisfactory for $\left(\mathrm{CD}_{2} \mathrm{CD}_{2} \mathrm{O}\right)_{2}$. In $\mathrm{D}_{2} \mathrm{O}$, however, deviation is somewhat more marked for ${ }^{3} J_{\mathrm{HH}}^{\prime}$, the same tendency being noted for DME ( $c f$. Figure 7).

\section{Analysis of the ${ }^{3} J_{\mathrm{CH}}$ Data}

As is shown in. Table II, the experimental values of ${ }^{3} J_{\mathrm{CH}}$ do not exceed $2 \mathrm{~Hz}$. Such observations immediately suggest that the $J_{\mathrm{G}}$ value defined in eq 3 may be fairly small in DME. The temperature dependence of ${ }^{3} J_{\mathrm{CH}}$ arises through the fraction term $f_{g}^{\mathrm{CO}}\left(=1-f_{t}^{\mathrm{CO}}\right)$ which may be treated by using eq 12 and 13 . In practice, for a given value of $E_{\rho}$, a set of $J_{\mathrm{G}}$ and

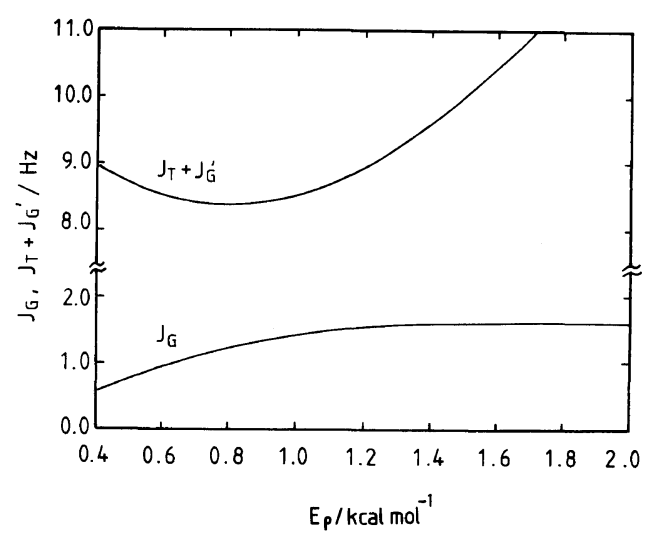

Figure 9. The best-fit values of $J_{\mathrm{G}}$ and $J_{\mathrm{T}}+J_{\mathrm{G}}^{\prime}$ plotted against $E_{\sigma}$ for DME in $c-\mathrm{C}_{6} D_{12}$.

$J_{\mathrm{T}}+J_{\mathrm{G}}^{\prime}$ was determined from the observed temperature dependence of ${ }^{3} J_{\mathrm{CH}}$ by the leastsquares method. In these calculations, the value of $E_{\sigma}$ was taken from the previous analysis. (As may be shown by some simple manipulation, what values we choose for $E_{\sigma}$ are relatively unimportant within the range $E_{\sigma}=0$ to $-1 \mathrm{kcal} \mathrm{mol}^{-1}$.) An example of the analysis (DME in $c-\mathrm{C}_{6} \mathrm{D}_{12}$ ) is shown in Figure 9 , where $J_{\mathrm{G}}$ and $J_{\mathrm{T}}+J^{\prime}{ }_{\mathrm{G}}$ thus obtained are plotted against $E_{\rho}$. For the $\mathrm{C}-\mathrm{O}$ bond, it has been known that the trans form exists predominantly in equilibrium: i.e., $f_{t}^{\mathrm{CO}}>f_{g}^{\mathrm{CO}} / 2$. As is suggested in eq $3,{ }^{3} J_{\mathrm{CH}}$ should vary more sensitively with alteration in the $J_{\mathrm{G}}$ value than with $J_{\mathrm{T}}+J_{\mathrm{G}}^{\prime}$. Over a range of $J_{\mathrm{G}}=1.0$ to $1.5 \mathrm{~Hz}, E_{\rho}$ varies from 0.6 to $1.2 \mathrm{kcal} \mathrm{mol}^{-1}$. At present, however, an unambiguous choice of $J_{\mathrm{G}}$ is difficult for DME. In view of the similarity in the chemical structure, the magnitude of the gauche coupling constant estimated for 1,4-dioxane $\left(\mathrm{CH}_{2} \mathrm{CH}_{2} \mathrm{O}\right)_{2}$ may be suggestive.

The observed value of ${ }^{3} J_{\mathrm{CH}}$ for 1,4-dioxane is $3.93 \mathrm{~Hz}$ in $c-\mathrm{C}_{6} \mathrm{D}_{12}$ : this value remains nearly invariant in most solvents over a wide range of temperature. In this compound, spatial arrangements around each skeletal $\mathrm{C}-\mathrm{C}$ or $\mathrm{C}-\mathrm{O}$ bond are approximately a regularly staggered conformation. The ${ }^{3} J_{\mathrm{CH}}$ under consideration corresponds to the sum of one half of the trans $\left(J_{\mathrm{T}}\right)$ and one half of the gauche coupling $\left(J_{\mathrm{G}}\right)$. 
Table VII. Values of $E_{\rho}$ for the C-O bond, estimated from the observed ${ }^{3} J_{\mathrm{CH}}$ by adopting $J_{\mathrm{G}}=1.3$ and $J_{\mathrm{T}}+J_{\mathrm{G}}^{\prime}=8.4 \mathrm{~Hz}$

\begin{tabular}{|c|c|c|c|}
\hline & \multirow{2}{*}{ Solvent } & Temp range & \multirow{2}{*}{$\frac{E_{\rho}}{\mathrm{kcal} \mathrm{mol}^{-1}}$} \\
\hline & & $\mathrm{C}$ & \\
\hline \multicolumn{4}{|l|}{ DME } \\
\hline & $c-\mathrm{C}_{6} \mathrm{D}_{12}$ & $40.0-100.0$ & 0.8 \\
\hline & $\left(\mathrm{CD}_{2} \mathrm{CD}_{2} \mathrm{O}\right)_{2}$ & $40.0-100.0$ & 0.8 \\
\hline & $\mathrm{CDCl}_{3}$ & $40.0-100.0$ & $1.1( \pm 0.1)^{2}$ \\
\hline & $\mathrm{CD}_{3} \mathrm{OD}$ & $40.0-80.0$ & 0.8 \\
\hline & $\left(\mathrm{CD}_{3}\right)_{2} \mathrm{SO}$ & $24.8-117.0$ & $0.8( \pm 0.1)^{2}$ \\
\hline & $\mathrm{D}_{2} \mathrm{O}$ & $24.8-102.0$ & $1.1( \pm 0.1)^{\mathrm{a}}$ \\
\hline \multicolumn{4}{|l|}{ POE } \\
\hline & $\left(\mathrm{CD}_{2} \mathrm{CD}_{2} \mathrm{O}\right)_{2}$ & $20.0-90.0$ & 1.0 \\
\hline & $\mathrm{D}_{2} \mathrm{O}$ & $40.0-92.0$ & $1.1( \pm 0.1)^{a}$ \\
\hline
\end{tabular}

a As the temperature increases, values of $E_{\rho}$ tend to decrease within the range indicated.

If we adopt a ratio $J_{\mathrm{G}} / J_{\mathrm{T}}=0.2$ as a lower limit acceptable for the proportion between these two couplings, ${ }^{21} J_{\mathrm{G}}$ may be as low as $1.3 \mathrm{~Hz}$. The value $\left(J_{\mathrm{G}}=1.8 \mathrm{~Hz}\right)$ derived by setting $J_{\mathrm{G}}$ $J_{\mathrm{T}}=0.3$ exceeds some of the experimentally observed values of ${ }^{3} J_{\mathrm{CH}}$ for DME, and therefore not instructive.

In DME, the gauche ${ }^{13} \mathrm{C}-\mathrm{O}-\mathrm{C}-{ }^{1} \mathrm{H}$ arrangement associated with the trans conformation of the $\mathrm{C}-\mathrm{O}$ bond is nearly regularly staggered. By setting $J_{\mathrm{G}}=1.3 \mathrm{~Hz}$, we obtain $J_{\mathrm{T}}+J_{\mathrm{G}}^{\prime}=8.4 \mathrm{~Hz}$ from the curve $\left(c-\mathrm{C}_{6} \mathrm{D}_{12}\right)$ in Figure 9 , leading to a value of $E_{\rho}=0.8 \mathrm{kcal}$ $\mathrm{mol}^{-1}$. Both $J_{\mathrm{T}}$ and $J_{\mathrm{G}}^{\prime}$ given above represent the couplings associated with the gauche conformation about the $\mathrm{C}-\mathrm{O}$ bond. The sum, $J_{\mathrm{T}}+J_{\mathrm{G}}^{\prime}=8.4 \mathrm{~Hz}$, is consistent with the corresponding value $(7.9 \mathrm{~Hz})$ of 1,4-dioxane, providing a sound ground for the present analysis. With reasons stated above, however, use of these parameters may lead to a somewhat lower estimate of $E_{\rho}$.

On the premise that the solvent effect on the coupling constants should be small, the same $J_{\mathrm{G}}$ and $J_{\mathrm{T}}+J_{\mathrm{G}}^{\prime}$ values were adopted in the analysis of the other experimental results. The conformational energy parameters $E_{\rho}$ obtain-

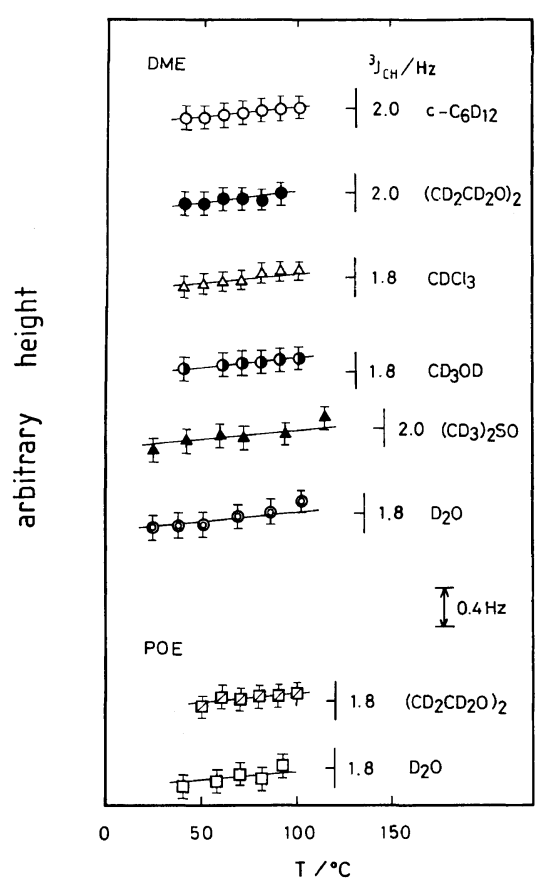

Figure 10. The temperature dependence of ${ }^{3} J_{\mathrm{CH}}$ for DME and POE. The curves drawn through the experimental points were calculated by using the best-fit values of $J_{\mathrm{G}}, J_{\mathrm{T}}+J_{\mathrm{G}}^{\prime}$ and $E_{\sigma}$. See legend to Figure 7 .

ed from the ${ }^{3} J_{\mathrm{CH}}$ data (Table II) by using eq 3 , 12, and 13 are summarized in Table VII. The values of $E_{\sigma}$ for $\mathrm{CDCl}_{3},\left(\mathrm{CD}_{3}\right)_{2} \mathrm{SO}$, and $\mathrm{D}_{2} \mathrm{O}$ exhibit some temperature dependence, and the results are indicated by the range. A similar treatment on the POE data yields results shown in the last two rows of Table VII. In these calculations, $f_{g}^{\mathrm{CO}}\left(=1-f_{t}^{\mathrm{CO}}\right)$ was evaluated by using eq 15 . The values of $E_{\rho}$ thus estimated for POE are in good correspondence with those obtained from DME in the same solvent. The compatibility of the parameters given in Table VII may be tested against the experimental ${ }^{3} J_{\mathrm{CH}} v s$. temperature data as shown in Figure 10. The observations are well reproduced by the calculated curves.

\section{DISCUSSION}

In the present treatment, the neighbordependent character of the bond rotation 
along the chain was rigorously taken into account in the expressions given by eq $10-15$. In the first step, the conformational energies $E_{\sigma}$ were tentatively deduced by adopting the values of $E_{\rho}$ calculated in the preceding section. The values of $E_{\sigma}$ thus deduced were used in the estimation of $E_{\rho}$ in the following step. In principle, such procedures should be iteratively repeated until a set of mutually consistent values of $E_{\sigma}$ and $E_{\rho}$ is obtained. However, $E_{\sigma}$ and $E_{\rho}$ were found to vary quite insensitively with each other: thus, in practice, iterations were terminated after the first trial. As previously discussed by Connor, ${ }^{8}$ the effect arising from the neighbor-dependence of the bond rotation is practically insignificant in DME as well as in POE. Both Viti et al. ${ }^{10}$ and Matsuzaki et al. ${ }^{9}$ have neglected contributions from the neighboring bond rotations in their treatment.

The values of $E_{\sigma}$ obtained for DME are negative, ranging from $-0.5\left(c-\mathrm{C}_{6} \mathrm{D}_{12}\right)$ to $-1.2 \mathrm{kcal} \mathrm{mol}^{-1}\left(\mathrm{D}_{2} \mathrm{O}\right)$ ( $c f$. Table VI). The magnitude of $E_{\sigma}$ tends to be larger in highly polar or hydrogen-bond-forming media. A similar trend was found by Viti et al. ${ }^{10}$ as well as Matsuzaki et al. ${ }^{9}$ The coupling constants $J_{\mathrm{T}}$ and $J_{\mathrm{G}}$ determined in this work are, however, somewhat different from those of the previous authors. ${ }^{9,10}$ Our values derived on the basis of a simplified two-parameter $\left(J_{\mathrm{T}}\right.$ and $\left.J_{\mathrm{G}}\right)$ model are $J_{\mathrm{T}}=11.4 \pm 0.3$ and $J_{\mathrm{G}}=2.3 \pm 0.1 \mathrm{~Hz}$. Viti et al. ${ }^{10}$ adopted Abraham's method, ${ }^{11}$ and deduced a set of coupling constants from the electronegativity (3.5) of the methoxyl group. In their procedure, the ${ }^{3} J_{\mathrm{HH}}$ data are entirely discarded on the ground that ${ }^{3} J_{\mathrm{HH}}$ is less sensitive to changes in temperature. In fact, conformational energies estimated from their ${ }^{3} J_{\mathrm{HH}}$ data by using their coupling constants $\left(J_{\mathrm{G}}=5.76\right.$ and $\left.J_{\mathrm{T}}^{\prime}+J_{\mathrm{G}}^{\prime \prime}=12.71 \mathrm{~Hz}\right)$ are positive (e.g., $E_{\sigma}^{\mathrm{s}}=0.6 \mathrm{kcal}^{\mathrm{mol}}{ }^{-1}$ for the neat liquid), contrary to the negative values $\left(E_{\sigma}^{\mathrm{s}}=\right.$ $-0.5 \mathrm{kcal} \mathrm{mol}^{-1}$ ) derived from the ${ }^{3} J_{\mathrm{HH}}^{\prime}$ data. This is an apparent inconsistency within their own treatment. Viti et al. ${ }^{10}$ employed the reaction field theory ${ }^{22}$ to elucidate the conformational energies $E_{\sigma}^{\mathrm{v}}$ for the vapor phase from those $\left(E_{\sigma}^{\mathrm{s}}\right)$ in solution. By definition, $E_{\sigma}^{\mathrm{v}}$ values obtained in various solvent systems should be constant, independent of polarity of the media. Their results indicate, however, that the $E_{\sigma}^{\mathrm{v}}$ value varies with the dielectric constant of the solvent as much as the $E_{\sigma}^{\mathrm{s}}$ does. Thus, estimation of the $E_{\sigma}^{\mathrm{v}}$ value in this manner is problematical.

In the ${ }^{3} J_{\mathrm{HH}}^{\prime} v s$. temperature plot shown in Figure 7, some systematic deviation is noted between the calculated curve and the experimental data points for solvents such as $\mathrm{CDCl}_{3}$, $\mathrm{CD}_{3} \mathrm{OD},\left(\mathrm{CD}_{3}\right)_{2} \mathrm{SO}$, and $\mathrm{D}_{2} \mathrm{O}$. These deviations may be corrected by adopting a somewhat larger $J_{\mathrm{T}}$ and a smaller $J_{\mathrm{G}}$ value in eq 2 . For this trial, we temporarily relax the conditions, $J_{\mathrm{T}}=J_{\mathrm{T}}^{\prime}$ and $J_{\mathrm{G}}=J_{\mathrm{G}}^{\prime}=J_{\mathrm{G}}^{\prime \prime}$. We note here that Matsuzaki et al.'s assignment ${ }^{9}\left(J_{\mathrm{T}}=\right.$ 21.1 and $J_{\mathrm{G}}^{\prime}=-1.5 \mathrm{~Hz}$ ) lies along this line. Changes of $J_{\mathrm{T}}$ and $J_{\mathrm{G}}$ required in the abovementioned amendment are, however, generally moderate, and the values do not exceed those of Matsuzaki et al. ${ }^{9}$ No such deviation was observed in nonpolar solvents such as $c-\mathrm{C}_{6} \mathrm{D}_{12}$ and $\left(\mathrm{CD}_{2} \mathrm{CD}_{2} \mathrm{O}\right)_{2}$, and in these cases, the agreement between the calculated and experimental results are satisfactory. Matsuzaki et al. ${ }^{9} \mathrm{ob}-$ tained $N$ and $L$ values directly from the observed spectrum without resort to any computer-aided spin analysis program. This would possibly be the major cause of the difference between their results and ours.

In the present analysis, the values of $J_{\mathrm{T}}$ and $J_{\mathrm{G}}$ were found to fall in the range usually adopted for the trans and gauche couplings, respectively. While these $J_{\mathrm{T}}$ and $J_{\mathrm{G}}$ values are not much affected by the solvent used, variation in the conformational energy $E_{\sigma}$ is sizable. The gauche form tends to be more stabilized as the dielectric constant of the medium increases. Such a phenomenon is known in common among 1,2-disubstituted ethanes carrying polar substituents: e.g., 1,2dihaloethanes. ${ }^{23}$ An increase in the gauche 
fraction was also observed in the hydrogenbond-forming solvent such as $\mathrm{CDCl}_{3}$ and $\mathrm{D}_{2} \mathrm{O}$ (cf. Table VI). From the recent Raman studies on POE in aqueous solution, Matsuura and Fukuhara ${ }^{24}$ suggested that the gauche arrangement, $\mathrm{O}-\mathrm{C} \in \mathrm{C}-\mathrm{O}$, may be stabilized by hydrogen-bonds with water molecules.

As for the conformational energy $E_{\rho}$ about the $\mathrm{C}-\mathrm{O}$ bond, no relevant experimental data are available for DME. Infrared and Raman studies $^{25}$ on some simple dialkyl ethers, such as diethyl ether or ethyl methyl ether, yielded conformational energies in the range from 1.1 to $1.5 \mathrm{kcal} \mathrm{mol}^{-1}$ for the difference between the gauche and trans states in the neat liquid, in solution, as well as in the gas phase. The results of electron diffraction studies ${ }^{26}$ on ethyl methyl ether led to a value of $1.2 \mathrm{kcal} \mathrm{mol}^{-1}$. As pointed out in the preceding section, our treatment essentially rests on what value we choose for $J_{\mathrm{G}}$. An increase in $J_{\mathrm{G}}$ by $0.1 \mathrm{~Hz}$ (thus, $J_{\mathrm{G}}=1.4 \mathrm{~Hz}$ ) enhances $E_{\rho}$ from 0.8 to $1.0 \mathrm{kcal} \mathrm{mol}{ }^{-1}$ in the $c-\mathrm{C}_{6} \mathrm{D}_{12}$ system. Ambiguity associated with the choice of $J_{\mathrm{G}}$ makes us reluctant to claim much accuracy for the present results. The numerical difference between simple ethers and DME may be insignificant. As shown in Table VII, the magnitude of $E_{\rho}$ tends to be slightly larger in $\mathrm{CDCl}_{3}$ and $\mathrm{D}_{2} \mathrm{O}$. An opposite trend was observed for the $\mathrm{C}-\mathrm{C}$ bond. With reasons stated above, however, quantitative discussions are improbable.

In the present analysis, we adopt a value of $\rho_{0}=0.61$ in the expression $\rho=\rho_{0} \exp \left(-E_{\rho} /\right.$ $R T$ ) ( $c f$. eq 18). This value was suggested from the results of the conformational energy calculations. If we tentatively employ a simple Boltzmann factor for $\rho$ by setting $\rho_{0}=1.0$, a value of $E_{\rho}=1.0 \mathrm{kcal} \mathrm{mol}^{-1}$ may be derived from otherwise the same analysis. The role of the preexponential factor is significant.

The effect arising from the alteration in the statistical weight factor $\omega$ was also examined. In practice, the value of $E_{\omega}$ was modified in the foregoing treatment. Since $\omega$ is always accompanied by $\rho(\ll 1)$ in eq 11 and 13 , neither $f_{g}^{\mathrm{CC}}$
$\left(=1-f_{t}^{\mathrm{CC}}\right)$ nor $f_{g}^{\mathrm{CO}}\left(=1-f_{t}^{\mathrm{CO}}\right)$ are affected significantly by changes of $E_{\omega}$ in the range $E_{\omega}=0.5 \pm 0.5 \mathrm{kcal} \mathrm{mol}^{-1}$

Conformational energies estimated from the observed temperature dependence of the coupling constants in $c-\mathrm{C}_{6} \mathrm{D}_{12}$ were found to be in a reasonable agreement with those calculated by using semiempirical potential energy functions in the preceding section. Fractions of various conformers can then be enumerated by using these expressions. Astrup $^{27}$ estimated fractions for several representative rotational isomers from the electron diffraction studies on DME in the vapor phase. Values of $f_{g}^{\mathrm{CC}}=0.77 \pm 0.12$ and $f_{t}^{\mathrm{CO}}=$ $0.63 \pm 0.06$ obtained from his results are in good agreement with our estimation. However, his analysis gave a larger fraction for $t g^{ \pm}$ $g^{ \pm}\left(+t g^{ \pm} g^{\mp}\right)(0.53 \pm 0.07)$ than $t g^{ \pm} t(0.23 \pm$ 0.07). This result is inconsistent with ours. The aforementioned agreement may thus be incidental.

Finally, we should emphasize that the $E_{\sigma}$ and $E_{\rho}$ values derived for POE exhibit a good correspondence with those for DME. These values are also in general agreement with those adopted previously in the calculation of conformation-dependent properties of the polymer chain. Kugler and Fisher ${ }^{28}$ carried out neutron scattering studies on mixtures of deuterated and undeuterated POE in the molten state. The characteristic ratio for the mean-square end-to-end distance is reported to be 6.9 . Whether or not this value exceeds those usually found in solution at the $\theta$ condition is controversial. Based on the information established in this work, molecular conformation of the POE chain will be examined in the forthcoming paper. ${ }^{12}$

Acknowledgement. The authors thank Prof. I. Ando of Tokyo Institute of Technology for valuable comments on the NMR spectroscopy, and Dr. Kushibiki and Mr. Hirakida of Showa Denko Co. for measuring the ${ }^{13} \mathrm{CH}$ satellite side band NMR spectra of DME. This 
work was supported in part by a Grant-in-Aid for Scientific Research from the Ministry of Education, Science, and Culture of Japan.

\section{REFERENCES AND NOTES}

1. A. Abe and J. E. Mark, J. Am. Chem. Soc., 98, 6468 (1976).

2. A. Abe, T. Hirano, and T. Tsuruta, Macromolecules, 12, 1092 (1979).

3. A. Abe, I. Ando, K. Kato, and I. Uematsu, Polym. J., 13, 1069 (1981).

4. J. E. Mark and P. J. Flory, J. Am. Chem. Soc., 87, 1415 (1965); J. E. Mark and P. J. Flory, ibid., 88, 3702 (1966).

5. P. J. Flory, "Statistical Mechanics of Chain Molecules," Interscience, New York, N.Y., 1969.

6. Y. Sasanuma, dissertation for master degree, Tokyo Institute of Technology, 1982.

7. H. S. Gutowsky, G. G. Belford and P. E. McMahon, J. Chem. Phys., 36, 3353 (1962).

8. T. M. Connor and K. A. McLauchlan, J. Phys. Chem., 69, 1888 (1965).

9. K. Matsuzaki and H. Ito, J. Polym. Sci., Polym. Phys. Ed., 12, 2507 (1974).

10. V. Viti, P. L. Indovina, F. Podo, L. Radics, and G. Némethy, Mol. Phys., 27, 541 (1974).

11. R. J. Abraham and G. Gatti, J. Chem. Soc., Sect. B, 961 (1969).

12. A. Abe and K. Tasaki, to be published

13. In the previous paper, ${ }^{1}$ we adopted notation $\sigma^{\prime}$ to designate the statistical weight for the $\mathrm{C}-\mathrm{O}$ bond. In this paper primes are used to distinguish the type of vicinal coupling constants. To avoid confusion, $\sigma^{\prime}$ is replaced by $\rho$.

14. In a more sophisticated scheme, torsional potentials are often expressed as a series of cosine terms such as

$$
E_{\text {tor }}(\phi)=\sum_{k}\left(\frac{1}{2}\right) E_{k}(1-\cos k \phi)
$$

A proper combination of $E_{1}, E_{2}$, and $E_{3}$ (with higher terms neglected) should yield a given gauche-trans energy difference. For the purpose at hand, however, introduction of a simple parameter $\Delta E$ should suffice. With the expression given in the text, the threefold character of the potential is retained. For the introduction of the $\Delta E$ term, the present treatment differs from our previous calculation and that of $F$. Podo et al. ${ }^{15}$

15. F. Podo, G. Némethy, P. L. Indovina, L. Radics, and V. Viti, Mol. Phys., 27, 521 (1974).

16. U. W. Suter and P. J. Flory, Macromolecules, 8, 765 (1975).

17. Gutowsky's original prescription ${ }^{7}$ involves simultaneous determination of $E_{\sigma}, J_{\mathrm{G}}$, and $J^{\prime}{ }_{\mathrm{T}}+J^{\prime \prime}{ }_{\mathrm{G}}$ by the nonlinear least-squares treatment. A similar attempt on the present data sometimes yields, fictitious values for the coupling constants. For elucidation of a reliable set of parameters, a more elaborate scheme is required.

18. The rule is generally valid for 1,2-disubstituted ethanes $\mathrm{XCH}_{2} \mathrm{CH}_{2} \mathrm{X}$, in which the size and polarity of $\mathrm{X}$ are moderate. ${ }^{19}$ Validity of such a semiempirical criterion has been confirmed by the FPT-INDO calculation as well (unpublished results).

19. R. J. Abraham and G. Gatti, J. Chem. Soc. Sect. B, 961 (1969).

20. N. Sheppard and J. J. Turner, Proc. R. Soc. London, Ser. A, 252, 506 (1959).

21. J. L. Marshall, "Carbon-Carbon and CarbonProton NMR Couplings," Verlag Chemie International, 1983; P. E. Hansen, Progress in NMR Spectroscopy, 14, 175 (1981).

22. R. J. Abraham and K. G. R. Pachler, Mol. Phys., 7, 165 (1963).

23. R. J. Abraham and E. Bretschneider, "Ințernal Rotation in Molecules," W. J. Orville-Thomas, Ed., John Wiley and Sons, 1974, Chapter 13.

24. H. Matsuura and K. Fukuhara, J. Mol. Struct., to be published.

25. H. Wieser, W. G. Laidlaw, P. J. Kruger, and H. Fuhrer, Spectrochim. Acta, A, 24, 1055 (1968); T. Kitagawa and T. Miyazawa, Bull. Chem. Soc. Jpn., 41, 1967 (1968); J. P. Perchard, J. Mol. Struct., 6, 457 (1970).

26. K. Oyanagi and K. Kuchitsu, Bull. Chem. Soc. Jpn., 51, 2237 (1978).

27. E. E. Astrup, Acta Chem. Scan., Ser. A, 33, 655 (1979).

28. J. Kugler, E. W. Fischer, M. Peuscher, and C. D. Eisenbach, Makromol. Chem., 184, 2325 (1983). 